This is the uncorrected proof of the following article: Vinterhalter B, Savić J, Zdravković-Korać S, Banjac $\mathrm{N}$, Vinterhalter D, Krstić-Milošević D. Agrobacterium rhizogenes-mediated transformation of Gentiana utriculosa $\mathrm{L}$. and xanthones decussatin-1-O-primeveroside and decussatin accumulation in hairy roots and somatic embryo-derived transgenic plants. Ind Crops Prod. 2019, which has been published in final form at http://doi.org/10.1016/J.INDCROP.2018.12.066. 


\title{
Agrobacterium rhizogenes-mediated transformation of Gentiana utriculosa L. and xanthones decussatin-1-O-primeveroside and decussatin accumulation in hairy roots and somatic embryo-derived transgenic plants
}

\author{
Branka Vinterhalter, Jelena Savić, Snežana Zdravković-Korać, Nevena Banjac, Dragan Vinterhalter, \\ Dijana Krstić-Milošević*
}

Institute for Biological Research, Department of Plant Physiology, University of Belgrade, Bulevar despota Stefana 142, Belgrade, 11000, Serbia

\section{A R T I C L E I N F O}

\section{Keywords:}

Agrobacterium rhizogenes

Decussatin

Genetic transformation

Gentiana utriculosa

Plant regeneration

Somatic embryogenesis

\begin{abstract}
A B S T R A C T
Production of innovative drugs from natural products in controlled conditions plays an important role in modern pharmacology in order to tackle global health challenges. The potential of Gentiana utriculosa hairy roots, obtained by transformation with Agrobacterium rhizogenes A4M70GUS, as well as that of the shoots regenerated from them via somatic embryogenesis, for xanthone production was investigated. Gentiana utriculosa was shown to be a new source of xanthones, medicinal raw materials for different pharmaceutical applications, among which decussatin has been recently recognized as a prospective hepatoprotective and antiulcer compound. Decussatin and decussatin-1-O-primeveroside were detected in both hairy roots and transgenic shoots, while mangiferin, present in nontransformed plants, was not detected. Quantitative HPLC analysis revealed up to 4.5-fold higher decussatin production in hairy roots line 9 compared with the plants from the nature, and this clone was selected. It showed stable growth after more than two years of continuous subcultivation. Cultivation of hairy roots on solid medium was favorable for biomass production, while liquid culture was beneficial for decussatin and decussatin-1-O-primeveroside accumulation. Cytokinins kinetin or $\mathrm{N}^{6}$-benzyladenine promoted somatic embryo maturation and germination as well as multiplication of obtained plantlets, while active charcoal reduced hyperhydricity. Plants regenerated from selected hairy root line 9 comprised two TL-DNA inserts, as confirmed by Southern blot analysis. They accumulated at least 2.5-fold more decussatin then nontransformed plants. Therefore, these plants could be valuable material to create xanthone high-yielding cultivars of $G$. utriculosa.
\end{abstract}

\section{Introduction}

Gentiana utriculosa L. is an annual plant species found in Central Europe, mainly in the Alps, Apennines, Croatia, Balkans and Transylvania (Köhlein, 1991; Tutin, 1972). It is a medium-sized herb, with deep azure-blue flowers, common and widespread in damp meadows and pastures from lowlands up to $2400 \mathrm{~m}$. It has wide distribution in the mountains of Central Serbia (Jovanović-Dunjić, 1977). The aerial parts of $G$. utriculosa are chemically characterized by the presence of xanthone-O-glycosides with 1,3,7,8-oxidation pattern along with xanthone and flavone- $C$-glucosides. Decussatin (1-hydroxy-3,7,8-trimethoxyxanthone) decussatin-1-O- primeveroside (1-O-primeverosyl-3,7,8-trimethoxyxanthone), together with mangiferin, gentiacaulein, and lancerin, were detected as the main xanthones (Janković et al., 2009). Since these compounds display a wide range of different biological activities, e.g. antimicrobial (Šavikin et al., 2009), radioprotective (Menković et al., 2010), antitumor (Isaković et al., 2008), antidepressant (Tomić et al., 2005) and vasodilator (Chericoni et al., 2003), G. utriculosa could be considered as a new potential source of medicinal raw materials for different pharmaceutical applications. Unlike the majority gentians, G. utriculosa has not been investigated in detail concerning its pharmacological properties and medicinal potential.

Moreover, xanthones mangiferin and decussatin, present in G. utriculosa, are nowadays recognized as promising hepatoprotec-

\footnotetext{
* Corresponding author.

Email address: dijana@ibiss.bg.ac.rs (D. Krstić-Milošević)
} 
tive compounds with strong potential to inhibit $\beta$-glucuronidase, the enzyme whose increased activity is responsible for carcinogenic transition and liver damage (Karak et al., 2017). Silymarin, a commercial Silybium marianum-derived mixture with $\beta$-glucuronidase inhibitory activity, used for years to treat liver disorders and related cancers (Kim et al., 1994; Dixit et al., 2007), has poor bioavailability (Dixit et al., 2007), and exhibits some negative effects related to gastrointestinal tract (Pradhan and Girish, 2006). Therefore, the report that decussatin displayed gastric cytoprotective and antisecretory properties in rats makes it an interesting compound for the development of new antiulcer drugs (Ateufac et al., 2014). Studies of Ateufac et al., (2007) have also shown the spasmogenic properties of decussatin on isolated gastric smooth muscle, and report that the mechanism of action might be due to an interference with calcium metabolism in smooth muscle.

Results of Ding et al., (2009) also showed that 1-hydroxy-3,7,8-trimethoxyxanthone displayed significant anti-proliferation and apoptosis effect in human leukemia cell line HL-60 in a time and dose-dependent manner. Therefore anticancer pharmacological activity of this xanthone was also suggested with conclusion that safety of dosage should be taken into consideration during the clinical treatment.

Discovering of the innovative drugs from natural products has played important role in modern pharmacology in order to tackle global health challenges (Atanasov et al., 2015). Multiple pharmacological effects of decussatin provide pharmacological support for its usage as a new potential medicine. However, although decussatin has attracted a special attention as natural product of therapeutic interest, its industrial application requires further pharmacological research as well as the suitable strategy for providing its sustainable resources.

The synthesis of biologically active metabolites in plants under the field conditions could be impaired by a number of external influences, causing the alterations in the quality and quantity of targeted metabolites and their production rates. Development of a reliable in vitro clonal propagation system could provide multiple benefits, e.g. to maintain stable and efficient secondary metabolite production, to facilitate studies on secondary metabolite production, to enable genetic improvement of plants and germplasm conservation. However, for many Gentiana species, protocols for such controlled propagation, leading to the satisfactory production of targeted secondary metabolites, have not yet been established. The protocol for in vitro shoot propagation and somatic embryogenesis of $G$. utriculosa has been reported for the first time by Vinterhalter et al., (2016). Despite intensive attempts to optimize tissue culture and regeneration parameters, the authors reported high levels of root and shoot hyperhydricity and necrosis, which subsequently impaired the quality, multiplication rates and growth potential of in vitro regenerated shoots, indicating the need for further procedure optimization.

Currently, the establishment of hairy roots by Agrobacterium rhizogenes-mediated transformation is considered as a promising approach to overcome the problems and limitations in secondary metabolites production of many plants (Matveeva and Sokornova, 2016; Alpizar et al., 2008; Mitić et al., 2012), as well as to develop superior genotypes with improved production of targeted metabolites e.g. higher xanthone norswertianin-1-O-primeveroside-producing clone of Gentiana dinarica (Vinterhalter et al., 2015) or selected clone (14-P) of Picrorhiza kurroa hairy root with higher potential for iridoid glycosides (picroside I and kutkoside) production (Verma et al., 2007, 2015). Hairy roots typically display fast growth and can be simply maintained on plant growth regulators (PGR)-free medium. They are genetically stable and plant regeneration from them occurs at high frequency in many plant species.
Somatic embryogenesis and plant regeneration from hairy roots have been reported in some valuable medicinal plants, including Gentiana macrophila (Wu et al., 2011), Panax quinquefolium (Zhao et al., 2012), and Salvia miltiorrhiza (Wang et al., 2013). According to the observed capacity of in vitro cultures to accumulate secondary metabolites, the establishment and maintenance of $G$. utriculosa hairy roots culture could be a desirable approach to meet increased pharmaceutical demands. Additionally, G. utriculosa hairy roots might also be used for clonal propagation of this plant species. Since the plants regenerated from hairy roots frequently have more robust root system than those of non-transformed or natural plants, hairy roots could be also used to improve rooting performances in regenerated plants.

On the basis of increasing medical significance of xanthone compounds, this research was initiated with the aim to establish hairy root cultures of $G$. utriculosa and to investigate their ability to produce xanthone compounds. Xanthone accumulation was also analyzed in transgenic plants derived from somatic embryos that spontaneously regenerated from hairy roots. The elite clone of $G$. utriculosa related to growth, regeneration performances and xanthones production was declared, paving the way for further research with the aim to intensify controlled xanthone production in G. utriculosa.

\section{Material and methods}

\subsection{Plant material, bacterial strain and transformation procedure}

in vitro-grown shoot cultures of Gentiana utriculosa L. (Vinterhalter et al., 2016) were used as material for genetic transformation. Aseptic shoot cultures, established from immature seeds (Vinterhalter et al., 2016), were maintained and multiplied on basal medium (BM) consisting of MS (Murashige and Skoog, 1962) mineral salts, LS (Linsmaier and Skoog, 1965) vitamins, $100 \mathrm{mg} \mathrm{L}^{-1}$ myo-inositol, $2 \%$ (w/v) sucrose, solidified with $0.64 \%(\mathrm{w} / \mathrm{v})$ agar (Torlak Institute of Virology, Vaccines and Sera, Belgrade, Serbia), and supplemented with $0.2 \mathrm{mg} \mathrm{L}^{-1} \mathrm{~N}^{6}$-benzyladenine (BA). Cultures of nontransformed roots, used for phytochemical analyses, were maintained in liquid BM media lacking agar, on an orbital shaker at $85 \mathrm{rpm}$. All plant cultures, either prior to or after the transformation, were grown under the controlled optimal cultivation conditions, at $25^{\circ} \mathrm{C} \pm 2{ }^{\circ} \mathrm{C}$ and under $16 \mathrm{~h}$ light $/ 8 \mathrm{~h}$ dark photoperiod provided by cool white fluorescent tubes with a flux rate of $40 \mu \mathrm{mol} \mathrm{s}^{-1} \mathrm{~m}^{-1}$ for shoots and $2 \mu \mathrm{mol} \mathrm{s}^{-1} \mathrm{~m}^{-1}$ for roots.

For plant tissue inoculation, Agrobacterium rhizogenes strain A4M70GUS, carrying the pRiA4 plasmid (Tepfer and Casse-Delbart, 1987), was used. This strain contains a cointegrative plasmid with a GUS construct integrated into the TL-DNA region of the pRiA4. GUS construct contains uidA sequence, coding for $\beta$-glucuronidase enzyme, under the $70 S$ promoter (enhancer-doubled 35S CaMV promoter), followed by nos polyadenylation sequence. Bacterial cultures were grown on solid YEB (Yeast Extract Beef) media (Van Larebeke et al., 1977) with $100 \mathrm{mg} \mathrm{L}^{-1}$ neomycin at $27^{\circ} \mathrm{C}$ in the dark for 3 days. For transformation purpose, overnight bacterial suspensions were made out of one full loop $(\varnothing$ $3 \mathrm{~mm}$ ) of bacterial culture scraped from a plate and re-suspended in $25 \mathrm{~mL}$ of a liquid YEB medium. After overnight incubation on an orbital shaker, A. rhizogenes cells were collected by centrifugation at $10,000 \mathrm{x}$ $g$, and pellet re-suspended in liquid YEB was used for inoculation.

Total of 197 explants, consisting of $15 \mathrm{~mm}$-long shoots, were inoculated by wounding with a needle dipped in bacterial suspension. Inoculated shoots (5 explants) were placed in $100 \mathrm{~mL}$ wide-neck Erlenmeyer flasks filled with $40 \mathrm{~mL}$ BM for the first 15 days of in- 
oculation and then transferred to BM supplemented with $300 \mathrm{mg} \mathrm{L}^{-1}$ Na-cefotaxime (Cef Tolycar®; Jugoremedia, Zrenjanin, Serbia).

Putative transgenic hairy roots were observed emerging three weeks after inoculation. Since most of them appeared to be fragile, each root was detached with the short piece of the initial explant and transferred into plastic Petri dish ( $\varnothing 100 \mathrm{~mm}$; Spektar, Čačak, Serbia) filled with $25 \mathrm{~mL}$ of solid $1 / 2 \mathrm{BM}$ (BM with half strength of MS mineral salts and vitamins), supplemented with $500 \mathrm{mg} \mathrm{L}^{-1}$ Cef. Hairy roots from each explant were separated as individual line. Hairy root cultures were maintained under the above described conditions, with the Cef concentration gradually decreasing in the subsequent 5-week long subcultures, down to the Cef-free medium after total of 6 subcultures.

\subsection{Histological analysis of somatic embryos development}

Material for histological analysis was fixed in FAA (formalin:acetic acid:ethanol 10:5:85 v/v/v), dehydrated in a graded ethanol series, subsequently cleared with xylol and embedded in paraffin wax at $58^{\circ} \mathrm{C}$. Sections $8-10 \mu \mathrm{m}$ thick were stained with haematoxylin and photographed using a Leitz DMRB photomicroscope (Leica, Wetzlar, Germany).

\subsection{Southern blot hybridization}

Southern hybridization was performed to confirm the stable integration of T-DNA and to estimate the copy number of the TL-DNA inserted within the genome of G. utriculosa. Plant genomic DNA was extracted from the shoots of transformed lines and nontransformed plants following the procedure of Murray and Thompson (1980), while plasmid pRiA4M70GUS DNA was extracted following the procedure of Kado and Liu (1981) and used as a positive control. DNA samples were digested with BglII endonuclease (Fermentas, Vilnius, Lithuania). One and a half $\mu \mathrm{g}$ of plant DNA samples and $20 \mathrm{ng}$ of plasmid DNA (quantified using a Qubit fluorometer, Invitrogen), were loaded on a $1 \%$ agarose gel (Sigma-Aldrich Co.), separated electrophoretically and blotted onto a positively charged nylon membrane (Roche, Indianapolis, IN, USA) by capillary transfer. Fragment of 478 bp was used as a probe for detection of the rolD gene, which is located in close proximity to the right TL-DNA border. The probe was labeled by PCR with digoxigenin (DIG)-dUTP (Roche), using forward primer 5'-CCT-TAC-GAA-TTC-TCT-TAG-CGG-CAC-C-3' and reverse primer 5'-GAG-GTA-CAC-TGG-ACT-GAA-TCT-GCA-C-3' (Fig. 3A).

Hybridization was performed in DIG Easy Hyb buffer (Roche) at $48^{\circ} \mathrm{C}$ for $16 \mathrm{~h}$. The membrane was then washed $2 \times 5 \mathrm{~min}$ in each of the following buffers: $2 x S S C+0.1 \%$ SDS (Sodium Dodecyl Sulfate) and $1 \mathrm{xSSC}+0.1 \%$ SDS at $48^{\circ} \mathrm{C}$ and $0.5 \mathrm{xSSC}+0.1 \%$ SDS and $0.1 \mathrm{xSSC}+0.1 \%$ SDS at $65-68^{\circ} \mathrm{C}$. Hybrids were detected with antidigoxigenin antibody (Roche), visualized with chemiluminescent substrate CDP-Star (Roche) and recorded on X-ray film (Kodak, Rochester, NY).

\subsection{Evaluation of hairy roots growth and regeneration potential}

To find the optimal conditions for hairy roots growth, elongated roots of three individual lines (4, 9 and 12) with confirmed integration of T-DNA, were further cultivated either in liquid or on solid $1 / 2 \mathrm{BM}$. For each individual line, hairy roots at initial weight of $400 \mathrm{mg}$ were cultivated in Erlenmeyer flasks with liquid medium or in plastic Petri dishes with solid medium. After 35 days, the fresh weight (FW) of roots was measured and the growth index (GI) was calculated as: GI = (final FW - initial FW) / initial FW.
The roots were then left to dry at room temperature, and the dry weight (DW) was recorded. On almost all tested roots, grown either in liquid or on solid media, spontaneous somatic embryogenesis occurred during these 35 days. The number of developed somatic embryos was determined under a stereomicroscope and presented as mean values per Erlenmeyer flask or Petri dish. For the solid medium, the effect of active charcoal (AC) at the concentration of $1 \mathrm{mg} \mathrm{L}^{-1}$ on all the abovementioned parameters of hairy roots growth was additionally tested.

\subsection{The effect of plant growth regulators on somatic embryo development}

Somatic embryos (SEs) regenerated from transgenic roots maintained either in liquid or on solid $1 / 2 \mathrm{BM}$, were detached and transferred onto the solid BM supplemented with $1 \mathrm{mg} \mathrm{mL}^{-1}$ AC without plant growth regulators (PGR) or with $0.1 \mathrm{mg} \mathrm{L}^{-1} \mathrm{~N}^{6}$-furfuryl aminopurine (kinetin, Kin) or $0.2 \mathrm{mg} \mathrm{L}^{-1} \mathrm{BA}$. After 35 days, the number of necrotic, hyperhydric, and healthy SEs germinated into plantlets, was recorded and presented as the percentage of total regenerated embryos.

In order to establish in vitro shoot cultures, viable germinated SEs were subsequently transferred onto the same solid BM media where hairy roots regenerating SEs were previously maintained. After 5 weeks, the number of axillary buds per plantlets were scored and presented as mean multiplication ratio ( $=$ main shoot + axillary buds for each group of plantlets obtained from SEs germinated on different media).

\subsection{Extraction and HPLC analysis of xanthones}

Xanthone identification and content determination were performed in extracts from in vitro-derived plantlets and wild growing plants, collected from two natural habitats located on Stara Planina mountain ( $1100 \mathrm{~m}$ ) in eastern Serbia (Loc 1) and Divčibare ( $980 \mathrm{~m}$ ) in western Serbia (Loc 2). The samples were air-dried at room temperature and ground to fine powder using a mortar and a pestle. The obtained powder $(500 \mathrm{mg}$ ) was extracted with $10 \mathrm{~mL}$ of methanol in ultrasonic bath for $20 \mathrm{~min}$. After sonication, extraction was continued by maceration in the dark at room temperature, for $48 \mathrm{~h}$. The extracts were filtered through Whatman filter paper No.1 into 10-mL volumetric flasks and adjusted to the volume with methanol. Prior to HPLC analysis, extracts were filtered through $0.45-\mu \mathrm{m}$ nylon syringe filters (Captiva Econo Filters, $13 \mathrm{~mm}$, Agilent Technologies).

Identification and quantification of xanthones were performed by chromatographic analysis (Agilent series 1100 HPLC instrument, with a diode array detector) on a reverse phase Zorbax SB-C18 (Agilent) analytical column ( $150 \mathrm{~mm} \times 4.6 \mathrm{~mm}$ i.d., $5 \mu \mathrm{m}$ particle size) thermostated at $25^{\circ} \mathrm{C}$. The mobile phase consisted of solvent A (1\%, v/v solution of orthophosphoric acid in water) and solvent B (acetonitrile, J.T. Baker, Deventer, The Netherlands). The separation of the components was performed using the gradient elution as follows: $98-90 \%$ A $0-5 \mathrm{~min}$, $90 \%$ A $5-10 \mathrm{~min}, 90-85 \%$ A $10-13 \mathrm{~min}, 85 \%$ A $13-15 \mathrm{~min}, 85-70 \%$ A $15-20 \mathrm{~min}, 70-40 \%$ A $20-24 \mathrm{~min}, 40-0 \%$ A $24-28 \mathrm{~min}$. Sample injection volume was $5 \mu \mathrm{l}$. Column elution was monitored at 260 and

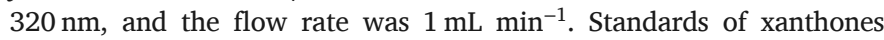
decussatin-1-O-primeveroside and decussatin were previously isolated in our laboratory from aerial parts of G. utriculosa (Janković et al., 2009). Mangiferin was purchased from Sigma-Aldrich Inc., Germany/ USA. Standard solutions for HPLC were prepared by dissolving xanthone compounds in methanol. Quantification was performed using calibration curves in external standard method. All experiments were 
repeated at least two times. The results are presented as $\mathrm{mg} \mathrm{g}^{-1}$ of DW of extracts.

\subsection{Statistical analysis}

The effects of genotype and nutrient media type or composition on parameters of transgenic hairy roots growth (GI, DW and number of SEs) and xanthone production were evaluated using two-way analysis of variance (ANOVA). Differences between the corresponding means were separated using Fisher's LSD test at $P \leq 0.05$. Additionally, Student's $t$-test was employed to compare the differences in xanthone content between nontransformed controls and transgenic lines (for each line and each growing condition vs. controls). For multiplication ratio comparison within each transgenic line, one-way ANOVA with nutrition media as a factor has been employed for both liquid and solid medium separately. Statistical analyses were performed using SAS software (SAS Institute, 2002; SAS/STAT, ver. 9.00. SAS Institute Inc., Cary, NC, USA).

\section{Results}

\subsection{Induction of Gentiana utriculosa hairy roots}

Three weeks after total of 197 in vitro-grown G. utriculosa shoot explants were inoculated with $A$. rhizogenes strain A4M70GUS, the first hairy roots appeared at the wounded sites (Fig. 1A), while 45 days after inoculation 21 of them $(10.66 \%)$ produced extensive, fibrous hairy roots, mostly without lateral branches and root hairs. The majority of detached roots was fragile, grew slowly and eventually became necrotic during cultivation on media supplemented with antibiotic Cef. Concomitantly, proliferated calli with green globules, as indicators of somatic embryo regeneration, were observed on some hairy roots (Fig. 1B).

Histological analysis of hairy roots indicated indirect somatic embryogenesis (Fig. 2). On the surface of hairy roots a parenchymatic callus tissue developed in which meristematic zones differentiated. Meristematic cells differed from surrounding parenchyma cells by dense, intensively stained cytoplasm and conspicuous nucleus with nucleolus (Fig. 2A,B). Anticlinal divisions of single cell in the surface layer indicated a unicellular origin of SEs (Fig. 2A). Proembryonic structures were observed on the surface of meristematic zones. SEs were separated with protoderm from neighboring tissues and did not have connections with vascular elements of roots (Fig. 2B, C). SE development was not synchronized since embryos at different developmental stages were simultaneously present in the same section (Fig. 2D, E). In bipolar structures, root and shoot meristematic cells at opposing poles are smaller and more in- tensively stained than the neighboring cells. In later torpedo and cotyledonary stage somatic embryos provascular elements are visible (Fig. 2D, F).

After 6 subsequent subcultures, when Cef was completely omitted from the nutrient media, 5 hairy root lines $(1,4,9,12$, and 13) (2.54\%) continued to grow. All these hairy root lines were subjected to molecular analyses to confirm their transgenic nature.

\subsection{Southern blot detection of transgenes}

Southern blot hybridization revealed the presence of 2-5 copies of the TL-DNA within the genomes in all 5 transformed lines (Fig. 3). All obtained fragments hybridizing with the probe were longer than the minimal expected size (4230 bp), indicating that all TL-DNA copies were of the full length. Positive control produced a band of approximately $9 \mathrm{~kb}$, while no signal was observed in nontransformed control.

The highest number of copies was recorded in lines 13 and 12 ( 4 and 5 , respectively), while two copies of TL-DNA were detected in lines 1, 4 and 9 (Fig. 3B).

\subsection{Phenotype of transgenic hairy roots and spontaneous somatic embryo regeneration}

Roots of transgenic lines exhibited significant phenotypic alterations and differed in their growth and regenerating potential both in liquid and on solid media (Fig. 4). When maintained on solid $1 / 2 \mathrm{BM}$, only hairy roots of the line 12 exhibited some of the typical "hairy root syndrome" characteristics: they were elongated, thick, with numerous lateral roots and with minor callus formation (Fig. 4A). By contrast, hairy roots of lines 4 and 9 were brittle, shorter and thicker, with weak lateral branching, and with more intensive callus formation, containing somatic embryos. Hairy roots of line 13 were mostly distinguished from the common hairy root phenotype, comprising thick and poorly growing roots, almost totally covered with large calli containing a lot of SEs, mainly clustered and hyperhydric, and providing limited amounts of available material for some of the following analyses.

The observed hairy root phenotype manifestations were further investigated on roots maintained in parallel in liquid and on solid $1 / 2 \mathrm{BM}$ (Fig. 4B). Type of the media and genotype, individually or conjoined, influenced the growth index, dry weight or number of regenerated SEs in different ways (Table 1). Solid media were less favorable for growth of hairy root line 4, but these roots had a higher dry weight than those maintained in liquid media. The opposite was observed for roots of line 9, where solid media facilitated growth, while the roots of line 12 grew equally well on both media

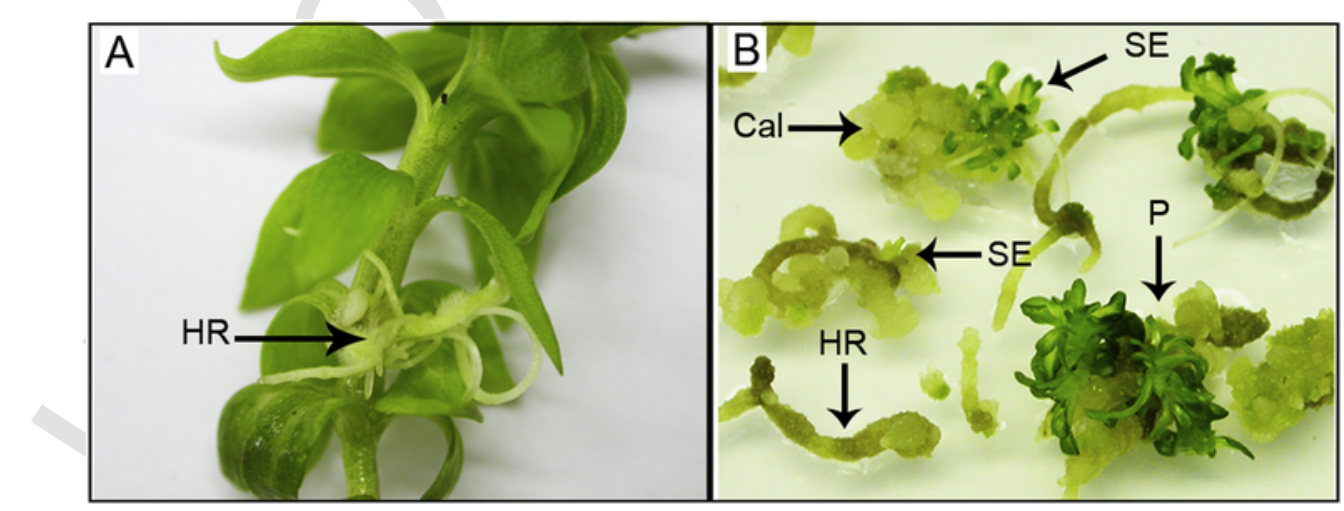

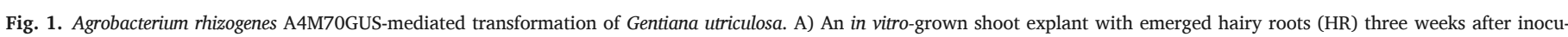

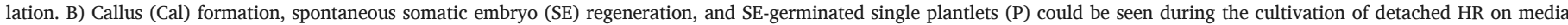
supplemented with cefotaxime. 


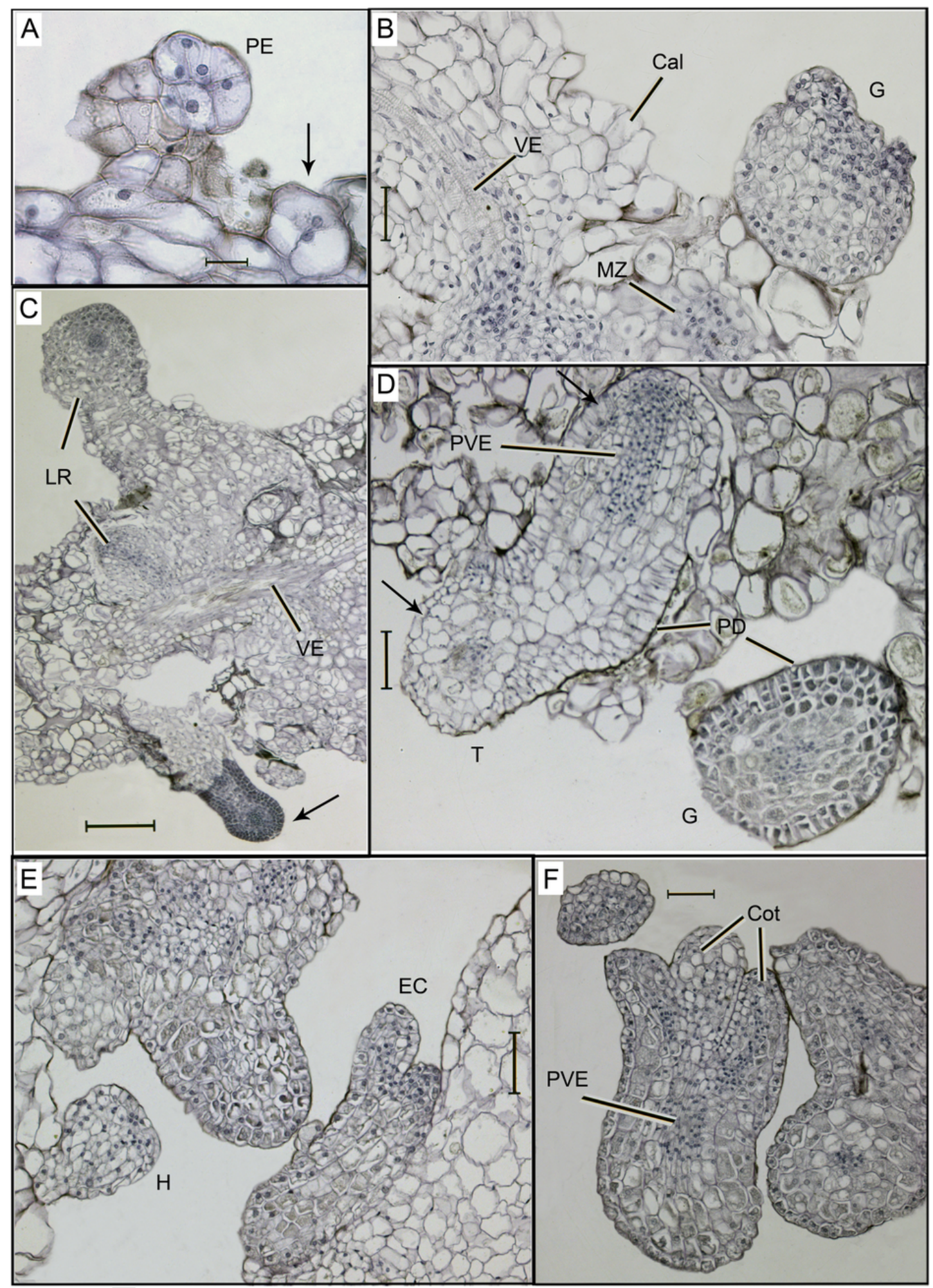

Fig. 2. Histological analysis of somatic embryogenesis from hairy roots of Gentiana utriculosa. (A) Anticlinal division of single cell in the surface layer of explant (arrow) and a five-cell proembryo; $b a r=20 \mu \mathrm{m}$. (B) and (C) Longitudinal section of a hairy root with differentiated vascular elements, callus, and meristematic zones, showing (B) somatic embryo at globular stage; bar $=50 \mu \mathrm{m}$, and (C) lateral roots and somatic embryo at cotyledonary stage (arrow); bar $=200 \mu \mathrm{m}$. (D) Globular and torpedo somatic embryos with protoderm on the surface. At torpedo stage shoot and root poles (arrows) and provascular elements are visible; bar $=100 \mu \mathrm{m}$. (E) Heart and early cotyledonary somatic embryos; bar $=80 \mu \mathrm{m}$. (F) Cotyledonary somatic embryo with cotyledons and provascular elements; bar $=80 \mu \mathrm{m}$. Proembryo (PE), provascular elements (PVE), vascular elements (VE), callus (Cal), protoderm (PD), meristematic zones (MZ), globular somatic embryos (G), torpedo somatic embryos (T), heart somatic embryos (H), early cotyledonary somatic embryos (EC), lateral roots (LR), (Cot) cotyledon. 
A

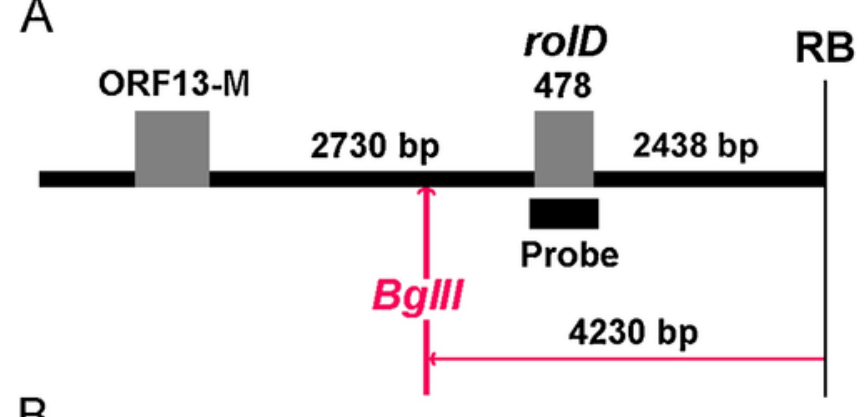

B

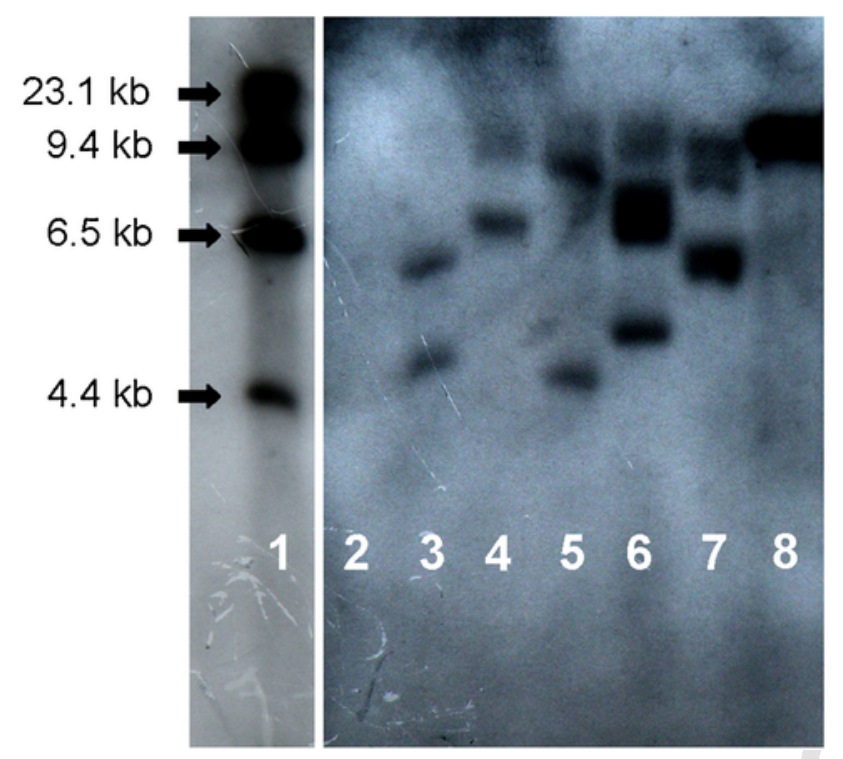

Fig. 3. Southern blot analysis of genomic DNA of putative transformed lines of Gentiana utriculosa, performed for TL-DNA copy number estimation. (A) A restriction map of the right part of the TL-DNA depicting the position of the rolD probe. (B) Genomic DNA was digested with BgII endonuclease and hybridized to the rolD probe. Lane 1: DNA molecular weight marker II (Roche Diagnostics Corporation) labelled with digoxigenin. Lane 2: Negative control, genomic DNA isolated from nontransformed plants. Lanes 3-7: Genomic DNA isolated from shoots of transformed lines 1, 4, 9, 12, and 13, respectively. Lane 8: Positive control, plasmid pRiA4M70GUS DNA digested with BgII endonuclease.

types. Hairy roots of line 9 showed the highest regeneration potential with the highest average number of SEs (27 per Erlenmeyer flask in liquid or 15 per Petri dish on solid medium).

The addition of AC into solid medium (Fig. 4C) improved root growth only in line 4, but without positive influence on root dry weight, and with negative impact on SE regeneration potential. Having no effect on GI and DW, AC addition halved the number of SEs in line 9.

\subsection{The effect of plant growth regulators on somatic embryo development}

During the cultivation of hairy roots in liquid or on solid $1 / 2 \mathrm{BM}$, spontaneous regeneration of SEs, either directly from the roots, or indirectly from calli formed on root sections, was observed. This process asynchronously occurred during the cultivation, thus different stages of SE development (from globular stage embryos to germinated plantlets) were observed on the same hairy root. A number of regenerated SEs displayed certain morphological malformations due to necrosis or hyperhydricity regardless of the type of the maintenance medium used (Fig. 5A).
The percentage of necrotic, hyperhydric and healthy SEs, as well as shoot regeneration potential depended on both hairy root line and the type of previously used maintenance nutrient media (Fig. 5B).

SEs isolated from the hairy roots cultivated in liquid BM displayed high percentage of necrosis, ranging from $56 \%$ in line 13 to nearly $80 \%$ in line 4 (Fig. 5B). Hairy root line 9 gave rise to the highest number of normal SEs (22.5\%), which developed into healthy plantlets during the next 5 weeks. On the other hand, SEs isolated from hairy roots cultivated on solid BM, exhibited significantly less morphological malformations than those grown in liquid medium (Fig. 5B). Only in line 13, the majority of SEs succumbed to necrosis. Although hyperhydricity of SEs occurred in all lines, the number of healthy looking SEs increased in comparison to liquid media. The highest number of healthy looking SEs was recorded in line 4 (40\%), as opposed to just 5\% of SEs in line 13.

To improve SE stability, both liquid and solid types of BM were supplemented with $0.1 \mathrm{mg} \mathrm{L}^{-1} \mathrm{KIN}$ or $0.2 \mathrm{mg} \mathrm{L}^{-1} \mathrm{BA}$. However, in liquid media, the number of necrotic SEs increased in 3 out of 4 analyzed lines (4, 12 and 13), while the number of healthy looking SEs decreased. Additional enrichment of cytokinin-containing media with AC caused the reduction of necrosis in lines 4 and 12 . The addition of cytokinins to solid media slightly affected distribution pattern of SE types, except for the line 4, where the addition of BA reduced the number of necrotic SEs ( $10 \%$ compared with $45 \%$ on $\mathrm{BM}$ ), as well as the number of healthy SEs (10\% compared with $40 \%$ on BM).

During the 5-week long cultivation, most of the healthy looking SEs germinated into plantlets (Fig. 5C) that were detached and individually cultivated on solid BM supplemented with AC and cytokinins. In general, these regenerated $G$. utriculosa transgenic plantlets displayed low multiplication ability in all analyzed lines (Fig. 5D). A few plantlets developed from the SEs obtained in liquid cultures multiplied sporadically. Multiplication pattern of plantlets, derived from SEs developed from hairy roots cultivated on solid media, was similar to that for SEs obtained from hairy roots cultivated in liquid medium. Mainly, the highest number of lateral buds was observed in lines 4 and 12 maintained on $\mathrm{BM}+\mathrm{KIN}+\mathrm{AC}$ (Fig. 5D).

Since KIN promoted development of healthy looking plantlets, it was used for further maintenance of $G$. utriculosa transgenic shoots. Subcultivation was performed in 5-week intervals on BM with $0.1 \mathrm{mg} \mathrm{L}^{-1}$ KIN and supplemented or not with $1 \mathrm{mg} \mathrm{L}^{-1} \mathrm{AC}$ (Fig. 6A), resulting in healthy looking rooted plants (Fig. 6B) that frequently flowered under in vitro conditions (Fig. 6C). Shoots often displayed different phenotypic appearance within the same line (Fig. 6D). All lines showed stable growth and multiplication for more than two years of in vitro culturing on abovementioned nutrition medium (data not shown). The mean multiplication ratio for lines 4, 12 and 13 ranged between 1.2-1.5, while plantlets of line 9 showed the highest mean multiplication ratio of 2.1 over this period and were with the most stabile phenotype characteristics.

\subsection{Xanthone production in hairy roots and regenerated plants}

Decussatin-1-O-primeveroside (2) and its corresponding aglycon decussatin (3) were found to be dominant xanthones in five-week-old hairy root lines $4,9,12$, and 13 , grown either in liquid or on solid $1 / 2 \mathrm{BM}$, as well as in the control nontransformed (NT) roots (Fig. 7). HPLC analysis also revealed the presence of xanthone- $C$-glucoside mangiferin (1), gentiakochianin-1-O-primeveroside (4), 1,8-dihydroxy-3-methoxy-7-O-primeveroside (5) and aglycons gentiakochianin (6) and gentiacaulein (7), mostly in lower amounts. 


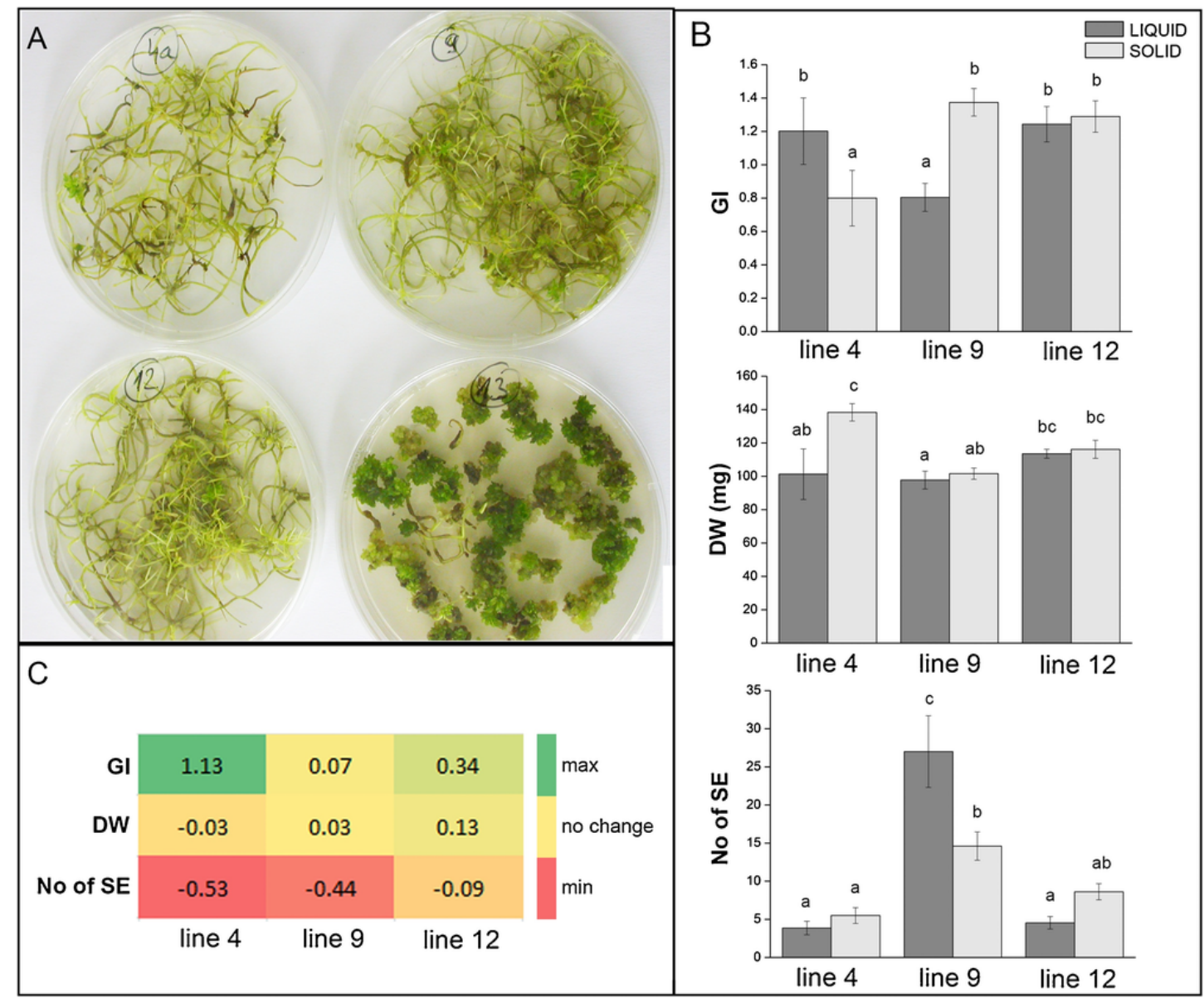

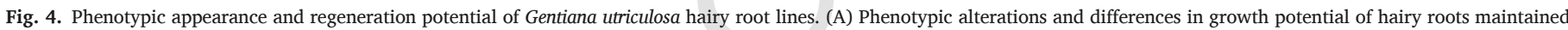

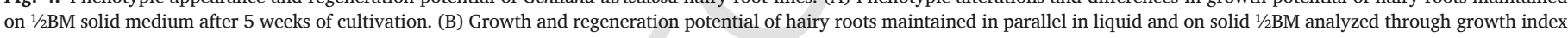

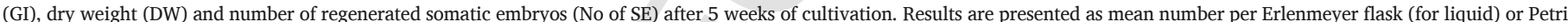

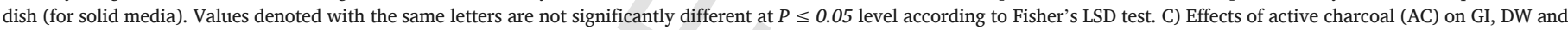
No of SE for roots maintained on solid media, were presented as relative values normalized to corresponding values for roots from media without AC (set as 1).

Table 1

Two-way ANOVA tables for the effect of nutrient media type, genotype and their combination on growth index (GI), dry weight (DW) and number of developed somatic embryos (SEs) of transgenic Gentiana utriculosa hairy root lines 4, 9 and 12.

\begin{tabular}{|c|c|c|c|c|}
\hline & df & Mean square & 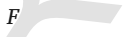 & $P$ \\
\hline \multicolumn{5}{|l|}{ GI } \\
\hline \multicolumn{5}{|l|}{ type of medium } \\
\hline & 1 & 0.122 & 0.5213 & 0.472 \\
\hline genotype & 2 & 0.593 & 2.5225 & 0.0854 \\
\hline type of medium $\mathrm{x}$ genotype & 2 & 1.812 & 7.7170 & 0.0007 \\
\hline $\begin{array}{l}D W \\
\text { type of medium }\end{array}$ & 1 & 2650.5 & 5.5811 & 0.0000 \\
\hline genotype & 2 & 2395.4 & 5.0440 & 0.0208 \\
\hline type of medium $x$ genotype & 2 & 1098.6 & 2.3130 & 0.1061 \\
\hline \multicolumn{5}{|l|}{ Number of SEs } \\
\hline type of medium & 1 & 119.5 & 0.9624 & 0.3289 \\
\hline genotype & 2 & 2736.0 & 22.0353 & 0.0000 \\
\hline type of medium $x$ genotype & 2 & 746.0 & 6.0082 & 0.0034 \\
\hline
\end{tabular}

Their chemical structures and chromatographic data are shown in Fig. 7.

The content of dominant xanthones in hairy roots differed among individual hairy root lines and between two different types on nutrient media for the roots of the same line, according to two-way ANOVA (Table 2). The most abundant xanthone in all roots, including transgenic lines, NT controls and plants from the nature, was decussatin-1-O-primeveroside (Fig. 7). Its amount ranged from 4.3 to $23.7 \mathrm{mg} \mathrm{g}^{-1} \mathrm{DW}$ and significantly differed among transgenic lines under the influence of nutrient media types, genotype and their interaction. The roots cultivated in liquid medium produced significantly higher amounts of decussatin-1-O-primeveroside compared with those grown on solid medium, with the highest content determined in lines 9 and 13. Additionally, decussatin-1-O-primeveroside accumulation was significantly different in all analyzed lines on both nutrient media (except for line 13 in liquid medium) compared with NT according to $t$-test. However, only roots of line 9 cultivated in liquid medium accumulated considerably enhanced amount of this xanthone $\left(23.74 \mathrm{mg} \mathrm{g}^{-1} \mathrm{DW}\right)$ in comparison to NT controls (18.23 $\left.\mathrm{mg} \mathrm{g}^{-1} \mathrm{DW}\right)$. The content of decussatin-1-O-primeveroside in roots of plants collected from the nature was similar for two distinct localities (10.35 and $10.26 \mathrm{mg} \mathrm{g}^{-1} \mathrm{DW}$ for Loc 1 and Loc 2, respectively) and lower than in both in vitro-grown NT roots and transgenic roots of line 9.

Similar pattern of accumulation has been observed for aglycone decussatin (Fig. 8). The highest accumulation of decussatin was again observed in lines 9 and 13, maintained in liquid media (6.10 and $3.64 \mathrm{mg} \mathrm{g}^{-1} \mathrm{DW}$, respectively). These concentrations were significantly higher compared with control roots $\left(1.81 \mathrm{mgg}^{-1} \mathrm{DW}\right.$, ac- 


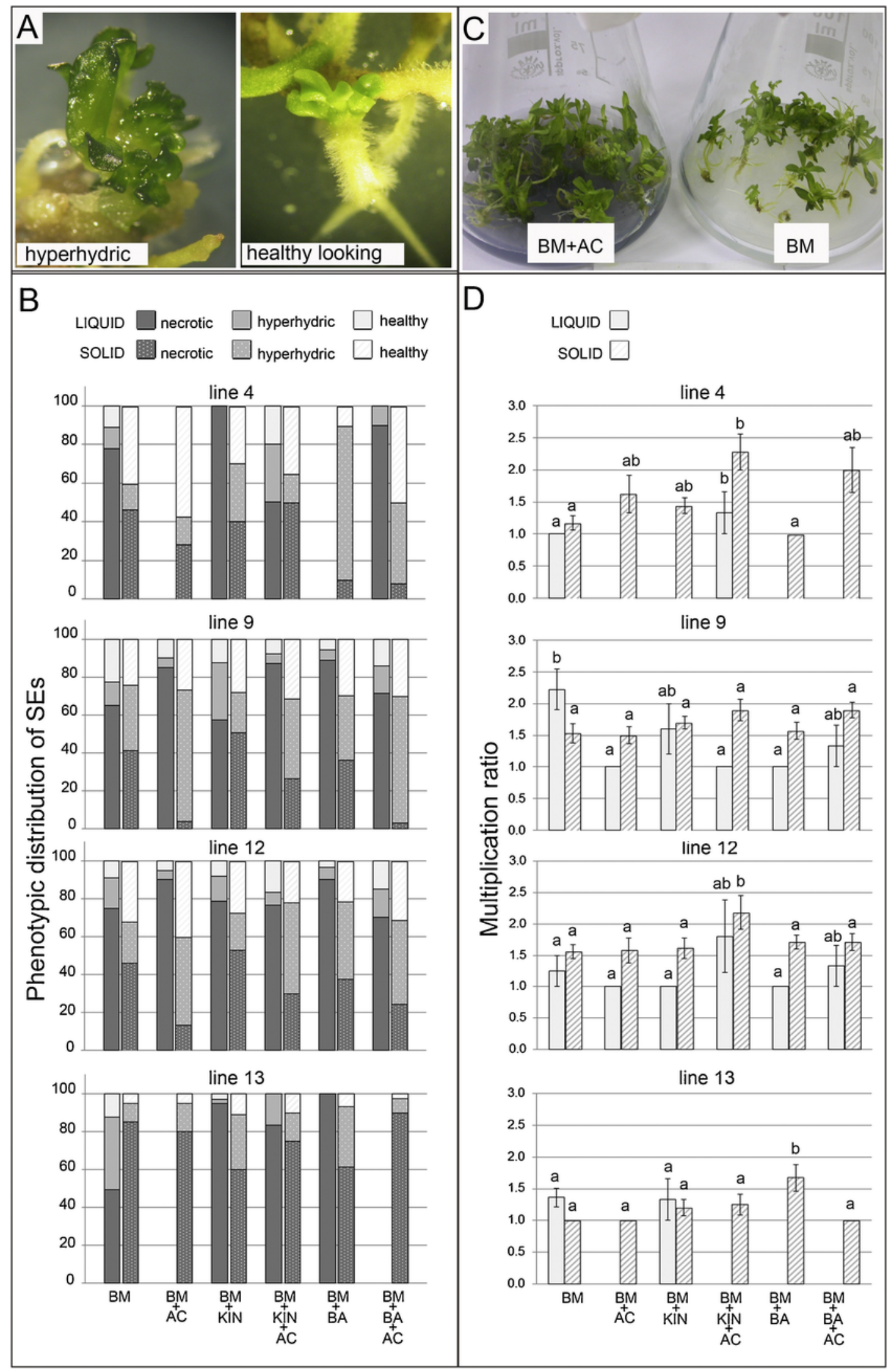

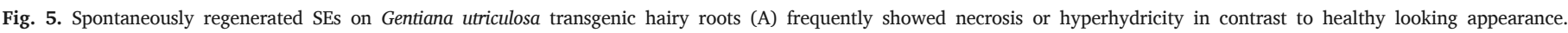

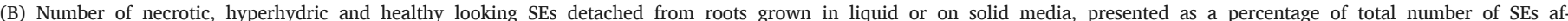

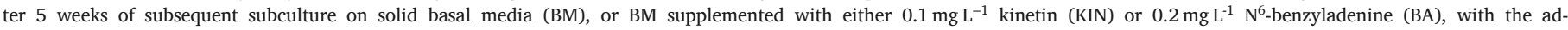

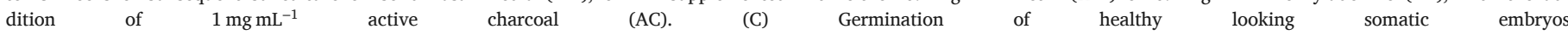




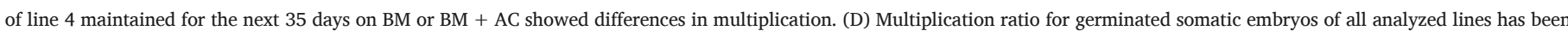

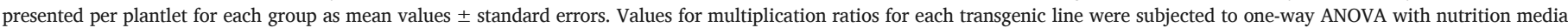
composition as factor for liquid or solid medium separately, and compared by Fisher's LSD test at $P \leq 0.05$.

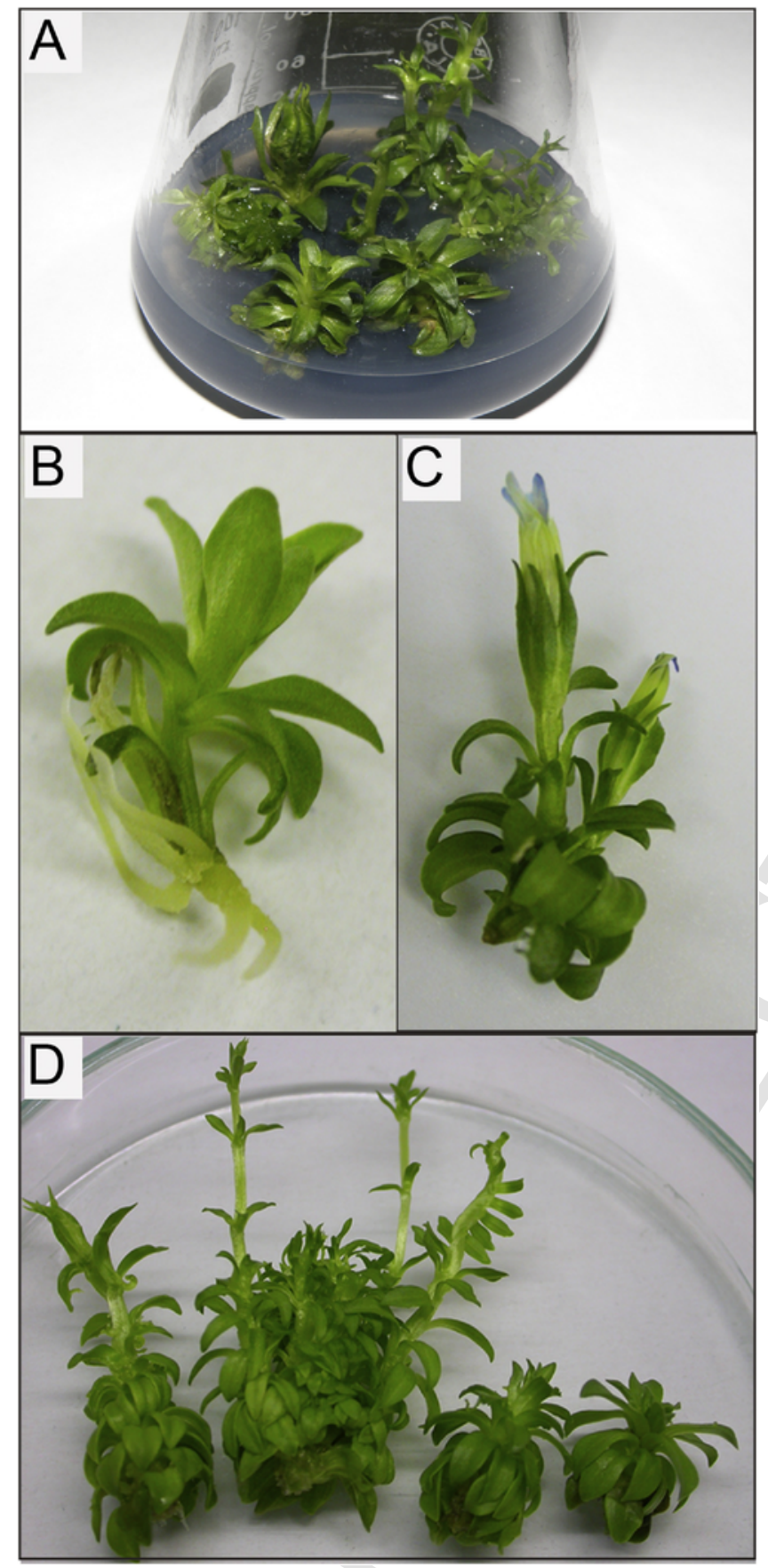

Fig. 6. In vitro cultures of transgenic Gentiana utriculosa line 9. (A) Plantlets maintained on KIN- supplemented BM with AC giving healthy looking rooted plants (B). (C) Flowering frequently occurred under in vitro conditions. (D) Plantlets of the same line often displayed morphological differences.

cording to $t$-test). Except for the roots of line 9 cultivated on solid media that contained high level of decussatin $\left(3.14 \mathrm{mg} \mathrm{g}^{-1} \mathrm{DW}\right)$, decussatin content in all other samples was similar to its level in NT roots. Although mangiferin has been detected in roots of plants collected from both localities, this xanthone was detected in small quantities $(\leq$ $0.1 \mathrm{mg} \mathrm{g}^{-1} \mathrm{DW}$ ) only in line 13 grown on solid media.
Xanthone content was also analyzed in five-week-old shoots of transgenic lines, NT control shoots and plants collected from the nature (Fig. 9). Decussatin-1-O-primeveroside, decussatin and mangiferin were detected and their content was found to be influenced by transgenic nature of lines, nutrient media and their interaction (Table 3). Decussatin-1-O-primeveroside was also dominant compound (Fig. 9) in all analyzed shoot samples. However, the content of decussatin-1-O-primeveroside was reduced compared with NT in almost all transgenic shoots with the exception of line 9 shoots, grown on PGR-free $\mathrm{BM}$, which produced slightly higher amount of this compound (8.13 $\left.\mathrm{mg} \mathrm{g}^{-1} \mathrm{DW}\right)$ than NT control $\left(7.40 \mathrm{mg} \mathrm{g}^{-1} \mathrm{DW}\right)$. Similar levels of decussatin-1-O-primeveroside were detected in both samples from the nature.

The shoots of line 9 grown on the same nutrient media also produced the highest amount of decussatin, exceeding $4.54 \mathrm{mg} \mathrm{g}^{-1}$ DW (Fig. 9). In shoots of all other transgenic lines, as well as in NT controls, its amount was below $2.10 \mathrm{mg} \mathrm{g}^{-1} \mathrm{DW}$. Decussatin was also present in both samples collected from the nature with the higher content detected for Loc 1, which was similar to that recorded in the most productive shoot line 9 grown on PGR-free BM.

Contrary to hairy roots where mangiferin was detected only in line 13, this compound was detected in shoots of all transgenic lines (Fig. 9) but at lower levels than in NT controls. Among transgenic lines, the shoots of line 12 cultured on cytokinin-free BM produced the highest amount of this compound (2.06 $\left.\mathrm{mg} \mathrm{g}^{-1} \mathrm{DW}\right)$. Mangiferin was the only analyzed xanthone whose content was higher in plants from the nature than in any of the in vitro-grown shoots.

\section{Discussion}

Although many factors can influence the effectiveness of $A$. rhizogenes-mediated transformation, the relationship between virulence ability of particular $A$. rhizogenes strain and plant genotype specificity is crucial for successful transformation (Opabode, 2006). Hairy root cultures of G. utriculosa were established using A4M70GUS strain, which was an appropriate vector for transformation of many Gentiana species, enabling transformation efficiency from $6.12 \%$ in $G$. dinarica (Vinterhalter et al., 2015) to even $63.4 \%$ in G. cruciata (Momčilović et al., 1997). Numerous $G$. utriculosa hairy root lines were obtained after inoculation with $A$. rhizogenes, five of which $(1,4,9,12$, and 13$)$ survived and gave rise to hairy root cultures. Therefore, with $2.54 \%$ transformation efficiency, $G$. utriculosa could be characterized as recalcitrant-to-transform species.

The high growth capacity and rapid biomass increment is the common characteristic of hairy root cultures in the majority of plant species. Thus, the most productive hairy root lines of $G$. dinarica and G. punctata, obtained using A4M70GUS strain, increased their biomass 7.8-fold (Vinterhalter et al., 2015) and 3.4-fold (Vinterhalter et al., 1999, 2000), respectively. In other Gentiana species, transformed with different $A$. rhizogenes strains, hairy root biomass increment ranged from 18.7-fold in G. macrophylla (Zhang et al., 2010) to 36-fold in G. scabra (Huang et al., 2014). However, the low growth index observed in liquid culture system of $G$. utriculosa (up to 1.2 after 35 days of cultivation) also pointed out at the recalcitrant nature of this species.

Additionally, hairy root cultures of $G$. utriculosa differed in growth potential and phenotypic characteristics. Although transgenic nature of these hairy root clones was confirmed by Southern blot analysis, they were characterized by relatively inferior 


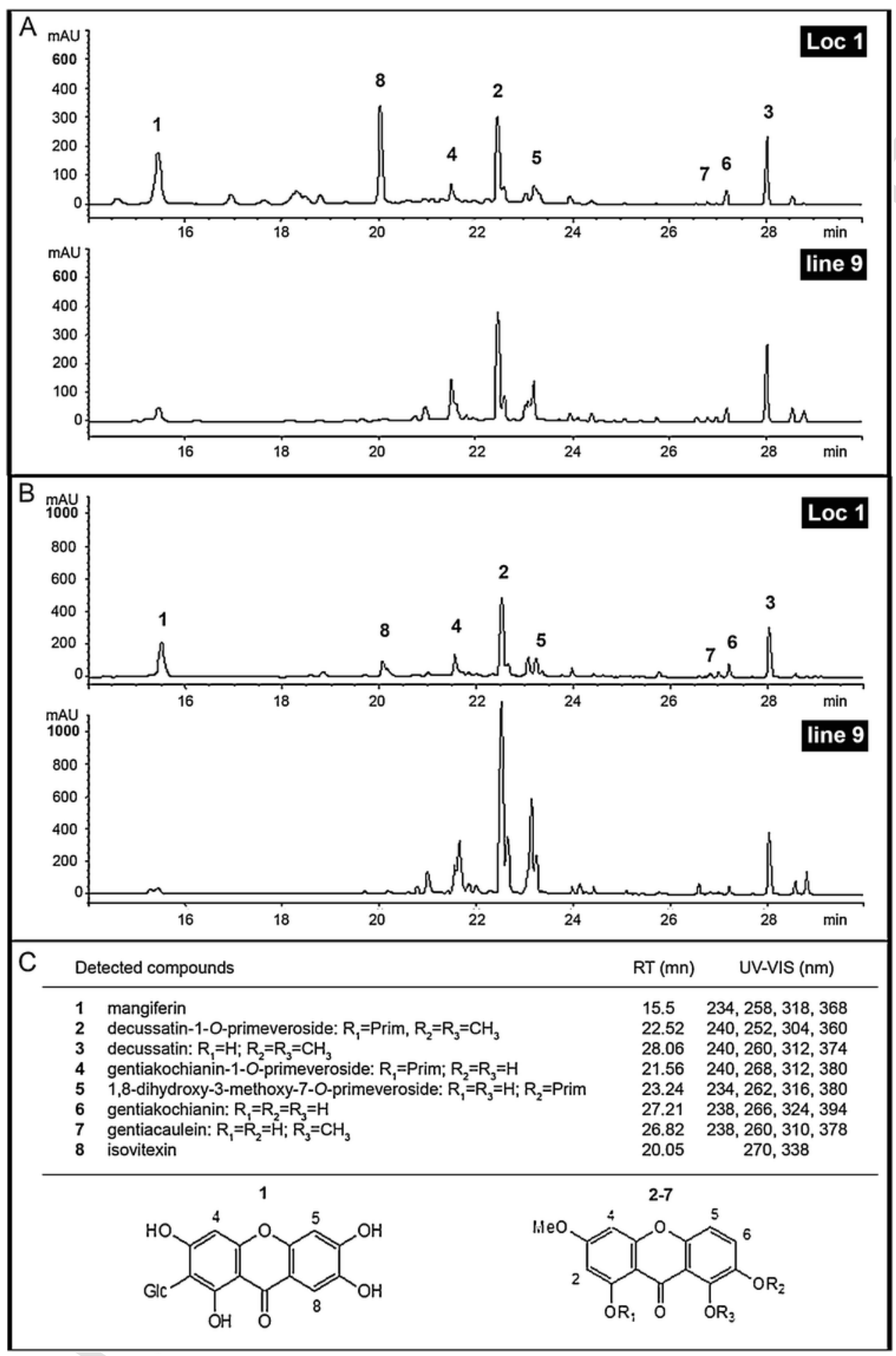

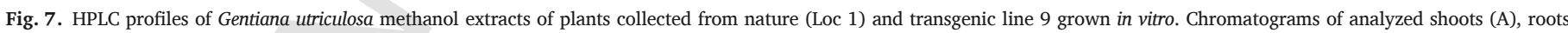
(B), and chemical structures with chromatographic data for detected compounds (C) were presented.

growth and atypical hairy root phenotype, considering the weak lateral branching (except for line 12) and root hairs. However, this is not exceptionality of $G$. utriculosa since the similar phenotypic characteristics were observed in hairy root clones of other Gentiana species (Vinterhalter et al., 1999).

The hairy root cultures have become fashionable biotransformation system for generation of new natural product derivatives with improved pharmaceutical properties (Srivastava et al., 2017). Hairy root cultures substrates of some medicinal plants, such as Panax ginseng (Kawaguchi et al., 1990; Ge et al., 2014) and Rhodiola kirilowii (Grech-Baran et al., 2014), have been explored for the bioconversion into the molecules of still improved pharmaceutical properties. Phytochemical analyses revealed that the secondary metabolite levels accumulated in hairy roots are often comparable to or greater than that of intact plants (Sevón and Oksman-Caldentey, 2002). G. utriculosa hairy roots displayed slightly modified xanthone metabolic profile compared with plants collected from the nature, related to mangiferin absence or undetectable 
Table 2

Two-way ANOVA tables for the effect of nutrient media type, genotype and their combination on xanthone content in transgenic Gentiana utriculosa hairy root lines 4, 9 and 12.

\begin{tabular}{|c|c|c|c|c|}
\hline & $\mathrm{df}$ & Mean square & $F$ & $P$ \\
\hline \multicolumn{5}{|l|}{ Decussatin-1-O-prim } \\
\hline type of medium & 1 & 555.57 & 30.755 & 0.00003 \\
\hline genotype & 3 & 41.87 & 2.3178 & 0.10993 \\
\hline type of medium $\mathrm{x}$ genotype & 3 & 43.546 & 2.4106 & 0.1105 \\
\hline \multicolumn{5}{|l|}{ Decussatin } \\
\hline type of medium & 1 & 2.175 & 8.2749 & 0.01004 \\
\hline genotype & 3 & 12.626 & 48.036 & 0.0000 \\
\hline type of medium $\mathrm{x}$ genotype & 3 & 4.947 & 18.8207 & 0.0000 \\
\hline
\end{tabular}

amounts in transgenic roots. On the other hand, hairy roots of line 9 produced up to 2.5-fold higher amount of decussatin-1-O-primeveroside and decussatin, compared with plants collected from two localities on Serbian mountains Stara planina and Divčibare, as well as significantly higher amounts of these compounds compared with nontransformed in vitro-maintained roots. Given that new findings suggest the beneficial pharmacological activities of decussatin (Ateufac et al., 2014; Karak et al., 2017), highly regenerating line 9 could be considered as a valuable tool for large scale production of this compound in a sustainable manner without environ- mental fluctuations (Veena and Taylor, 2007; Banerjee et al., 2012).

Hairy roots can regenerate whole plants, which has been reported in some medicinal plants including Panax ginseng (Yang and Choi, 2000), Catharanthus roseus (Choi et al., 2004), Crotalaria spectabilis (Ohara et al., 2012), and Salvia miltiorrhiza (Wang et al., 2013). In G. utriculosa, spontaneous somatic embryos regenerated immediately after the hairy roots have been isolated from explant tissue and cultivated individually. The regeneration of somatic embryos from hairy roots occurs rarely in Gentiana, and up to date has been reported only in G. macrophylla (Wu et al., 2011). The hairy roots of G. cruciata (Momčilović et al., 1997), G. macrophylla (Zhang et al., 2010) and G. punctata (Vinterhalter et al., 1999) spontaneously regenerated shoots rather than somatic embryos, while G. purpurea, G. scabra, G. triflora x G. scabra required the use of different plant growth regulators for shoot regeneration (Suginuma and Akihama, 1995; Momčilović et al., 1997; Mishiba et al., 2006).

Although somatic embryogenesis in G. utriculosa occurred on PGR-free media, addition of cytokinins (KIN or BA) at low concentration promoted SE maturation and germination as well as the multiplication of obtained plantlets. In addition, activated charcoal, known as a good absorbent of inhibitory compounds excreted in the medium, is often used to stimulate somatic embryogenesis, androgenesis, micropropagation, protoplast culture, rooting, elongation, synthetic seed production, etc. (Thomas, 2008). However, in G. utriculosa AC seemingly displayed dual effect, stimulating SE

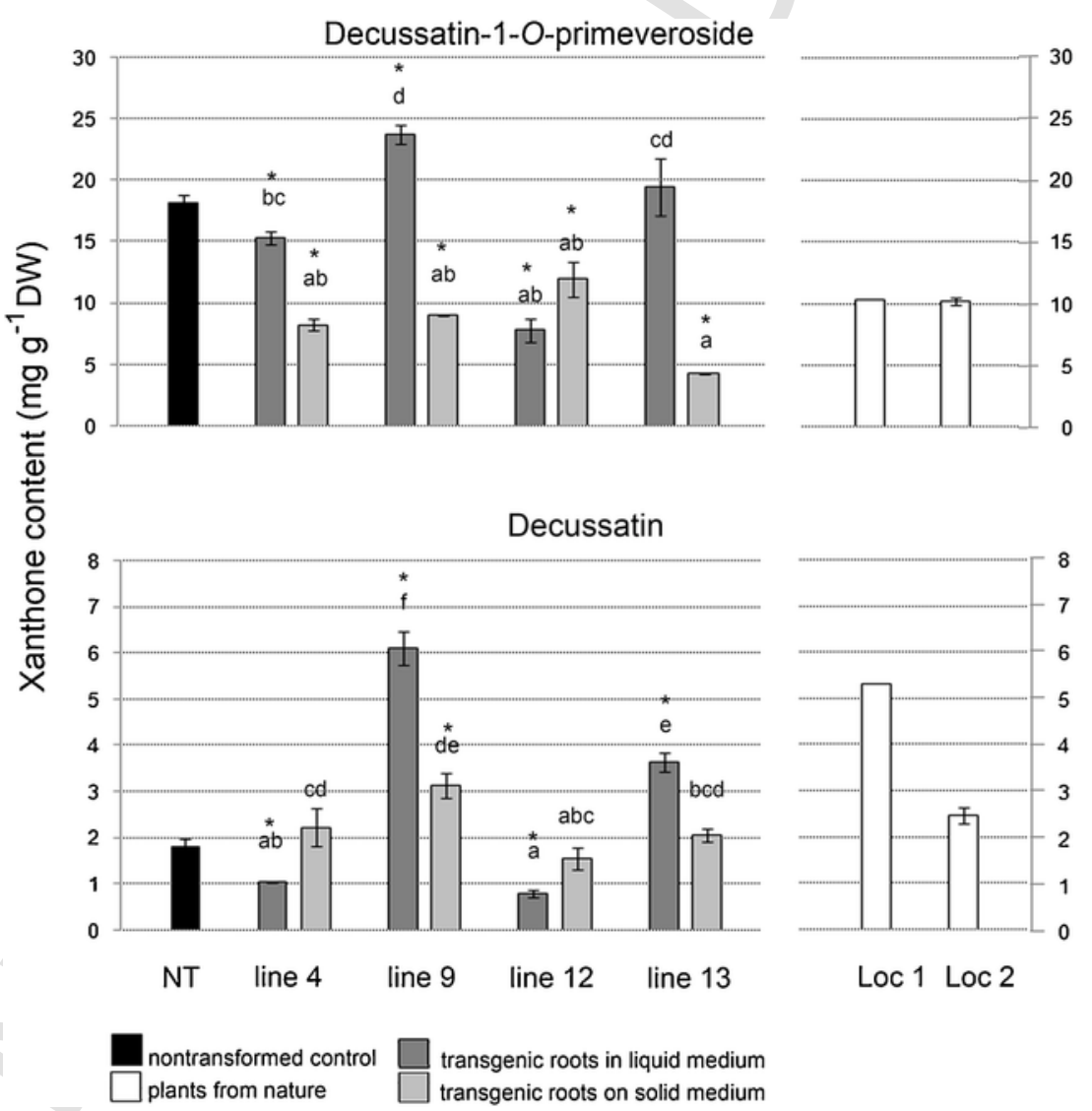

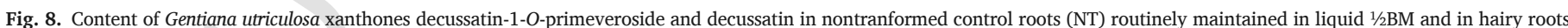

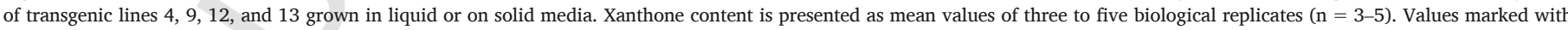

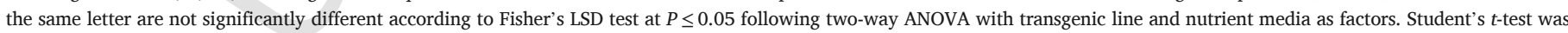

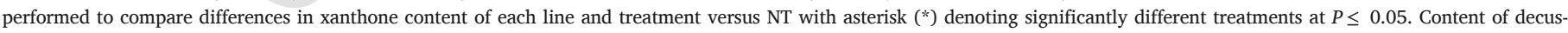
satin-1-O-primeveroside and decussatin in plant roots collected from the nature from two different localities (Loc 1 - Stara planina and Loc 2 - Divčibare) is presented in addition. 


\section{Decussatin-1-O-primeveroside}
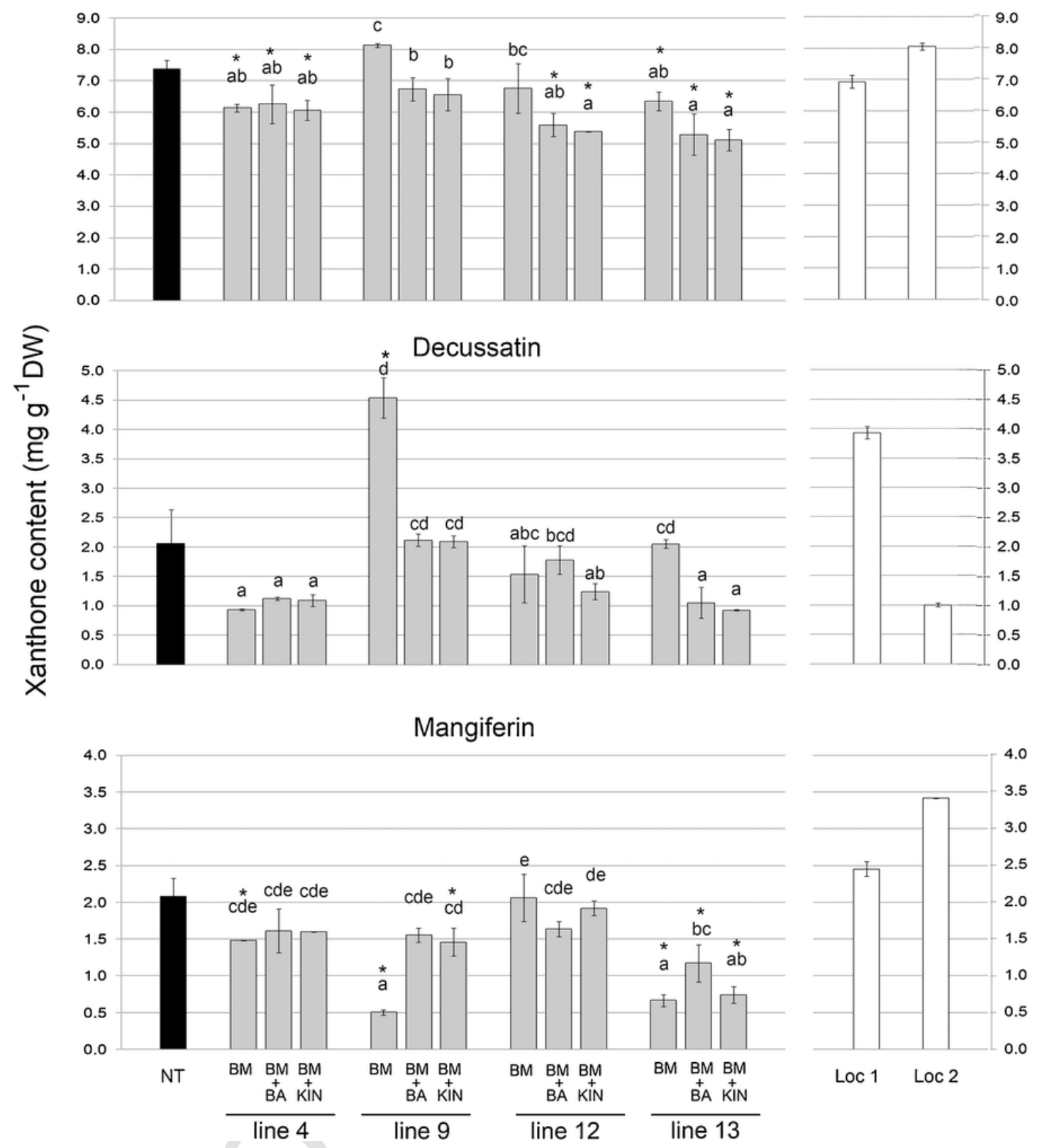

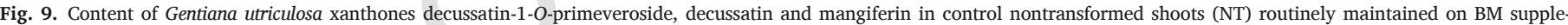

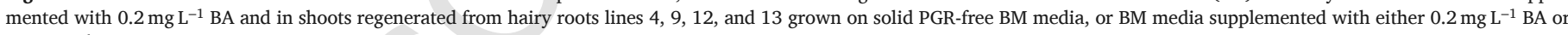

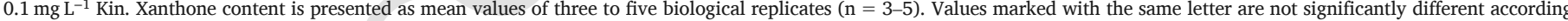

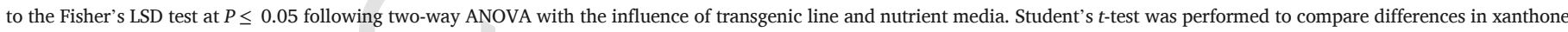

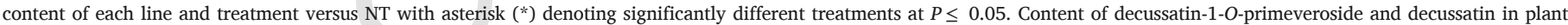
shoots collected from the nature from two different localities (Loc 1- Stara planina and Loc 2- Divčibare) were presented in addition.

germination and growth and diminishing hyperhydricity of obtained plants on one hand, and inhibiting spontaneous SE induction on the other hand.

The plants regenerated from hairy roots are often phenotypically different from their mother plants, commonly having wrinkled leaves, increased branching and rooting, shortened internodes, reduced apical dominance, and altered flowering (Tepfer, 1984, 1990). Phenotypic dissimilarity was observed among transgenic G. utriculosa plant lines but also within the same line, and it varied from short-rosette form (most of the line 13 plantlets) to nicely elongated (most of the line 9 plantlets) and flowering shoots (most of the line 4 plantlets).

More importantly, some hairy root-derived plants can produce higher amounts of secondary metabolites. The content of gentiopicroside in G. macrophylla plants, obtained through somatic embryogenesis from hairy roots, rose by $72.4 \%$ compared with wild type (WT) plants (Wu et al., 2011). Similarly, the hairy root-derived plants of Plumbago indica had increased plumbagin content relative to nontransformed plants (Gangopadhyay et al., 2011; Martin et al., 2011), those regenerated from Tylophora indica accumulated 20-60\% higher augmented tylophorine content (Chaudhuri et al., 
Table 3

Two-way ANOVA tables for the effect of nutrient media type, genotype and their combination on xanthone content in lines 4, 9 and 12 of in vitro grown shoots of transgenic Gentiana utriculosa.

\begin{tabular}{|c|c|c|c|c|}
\hline & df & Mean square & $F$ & $P$ \\
\hline \multicolumn{5}{|l|}{ Decussatin-1-O-prim } \\
\hline type of medium & 2 & 2.2 & 4.669 & 0.0242 \\
\hline genotype & 3 & 4.144 & 8.796 & 0.0009 \\
\hline type of medium $\mathrm{x}$ genotype & 6 & 0.339 & 0.72 & 0.6389 \\
\hline \multicolumn{5}{|l|}{ Decussatin } \\
\hline type of medium & 2 & 2.0574 & 22.7433 & 0.0000 \\
\hline genotype & 3 & 5.1034 & 56.4156 & 0.0000 \\
\hline type of medium $x$ genotype & 6 & 1.0535 & 11.6457 & 0.0000 \\
\hline \multicolumn{5}{|l|}{ Mangiferin } \\
\hline type of medium & 2 & 0.3244 & 4.2595 & 0.0316 \\
\hline genotype & 3 & 1.5444 & 20.2761 & 0.0000 \\
\hline type of medium $\mathrm{x}$ genotype & 6 & 0.2594 & 3.4061 & 0.0215 \\
\hline
\end{tabular}

2006), while total tanshinone content in Salvia miltiorrhiza hairy root-derived plants was 1.8-fold and 4.7-fold higher compared with that of WT plants (Wang et al., 2013). It has been reported that the expression of rol genes in hairy root-regenerated plants induced the accumulation of secondary metabolites such as gentiopicroside (Wu et al., 2011) and tylophorine (Chaudhuri et al., 2006). The observed changes in phenotype and secondary metabolite production/accumulation profile might be due to position effect of T-DNA and transgene stability within plant genome, as well as the effect of Rol proteins on signal transduction and regulation of gene expression within the plant cell (Bulgakov, 2008, 2016; Dubrovina et al., 2009; Taneja et al., 2010; Mauro et al., 2017). Although the TL-DNA copy number in G. utriculosa clones varied from two to five, decussatin high-yielding plants contained two copies only, indicating that the higher number of T-DNA inserts does not necessarily lead to an enhanced potential for secondary metabolite production. No correlation between TL-DNA copy numbers and artemisin content was found in Artemisia annua either, where hairy root line A1 with single T-DNA insert was shown to have higher growth rate and artemisin content compared with clones that contained multiple copies (Ahlawat et al., 2014).

G. utriculosa decussatin high-yielding plants were regenerated from superior hairy root line 9, and produced the highest content of this compound. Plants of this line were also characterized by the production of decussatin-1-O-primeveroside at the similar level to the plants from nature, as well as of mangiferin, which was previously not detected in the hairy roots of the same line, at significantly lower level. Although the use of cytokinins BA and KIN partly enhanced mangiferin production, they were not favorable for the accumulation of two other xanthones, decussatin and decussatin-1-O-primeveroside. Since A. rhizogenes-produced transformants are mitotically stable (Lacroix et al., 2006), selected plants regenerated from G. utriculosa hairy roots line 9 may develop into a new cultivar for large scale production of xanthones decussatin and decussatin-1-O-primeveroside.

For future work, selected G. utriculosa hairy root culture could be subjected to enzymatic activity of different biological systems (Jiao et al., 2018) that can lead to hydrolysis of decussatin-1-O-primeveroside, enabling enhanced decussatin production. Hairy root culture system could also be used as a substrate for the biotransformation of decussatin into the molecules with enhanced pharmacological properties, such as its derivatives with P-glycoprotein modulator activity (Noungoue Tchamo et al., 2001). Selected elite hairy root lines can be encapsulated using synthetic seed technology and stored for prolonged time while conserving high regeneration potential and secondary metabolite production (Gangopadhyay et al., 2011), which would facilitate their industrial use.

\subsection{Conclusions}

In conclusion, hairy roots as a valuable tool for sustainable production of xanthones were established in G. utriculosa using A. rhizogenes A4M70GUS strain. One of the five obtained clones was shown to produce and accumulate more than 4.5-fold higher amount of xanthone decussatin, in comparison to plants from the nature. Plants of G. utriculosa line 9, exhibiting stable growth for more than two years, can be considered as a favorable system for sustainable production of decussatin. It could also be a source for new bioactive substances production using biotransformation. Transgenic plants, spontaneously regenerated from this elite hairy root line through somatic embryogenesis, contained two TL-DNA copies as confirmed by Southern analysis, and displayed enhanced productivity of decussatin. Therefore, they could be valuable material to create xanthone high-yielding cultivars, which could be additionally remade by introduction of desirable genes or by modification of metabolic pathways using $A$. rhizogenes-mediated transformation.

\section{Acknowledgment}

This research was funded by the Ministry of Education, Science and Technological Development of the Republic of Serbia (Grant No. OI173015).

\section{References}

Ahlawat, S., Saxena, P., Alam, P., Wajid, S., Abdin, M., 2014. Modulation of artemisinin biosynthesis by elicitors, inhibitor, and precursor in hairy root cultures of Artemisia annua L.. J. Plant Interact. 9, 811-824.

Alpizar, E., Dechamp, E., Lapeyre-Montes, F., Guilhaumon, C., Bertrand, B., Jourdan, C., Lashermes, P., Etienne, H., 2008. Agrobacterium rhizogenes-transformed roots of coffee (Coffea arabica): conditions for long-term proliferation, and morphological and molecular characterization. Ann. Bot. 101, 929-940.

Atanasov, A.G., Waltenberger, B., Pferschy-Wenzig, E.-M., Linder, T., Wawrosch, C., Uhrin, P., Temml, V., Wang, L., Schwaiger, S., Heiss, E.H., Rollinger, J.M., Schuster, D. Breuss, J.M., Bochkov, V., Mihovilovic, M.D., Kopp, B., Bauer, R., Dirsch, V.M., Stuppner, H., 2015. Discovery and resupply of pharmacologically active plant-derived natural products. Biotechnol. Adv. 33 (8), 1582-1614.

Ateufac, G., Nguelefack, T.B., Mbiantacha, M., Tane, P., Kamanyi, A., 2007. Spasmogenic activity of 1-Hydroxy-3,7,8-trimethoxyxanthone isolated from the methanol extract of the stem bark of Anthocleista vogelii Planch. (Loganiaceae) in rats. Pharmacologyonline 3, 374-384.

Ateufac, G., Nguelefack, T.B., Wabo, H.K., Tane, P., Kamanyi, A., 2014. Antiulcerogenic activity of 1-Hydroxy-3,7,8-trimethoxyxanthone isolated from the methanol extract of Anthocleista vogelii PLANCH. In rats. Ulcers 1-6.

Banerjee, S., Singh, S., Rahman, L.U., 2012. Biotransformation studies using hairy root cultures - a review. Biotechnol. Adv. 30 (3), 461-468.

Bulgakov, V.P., 2008. Functions of rol genes in plant secondary metabolism. Biotechnol. Adv. 26, 318-324.

Bulgakov, V.P., Veremeichik, G.N., Grigorchuk, V.P., Rybin, V.G., Shkryl, Y.N., 2016. The rolB gene activates secondary metabolism in Arabidopsis calli via selective activation of genes encoding MYB and bHLH transcription factors. Plant Physiol. Biochem. 102, 70-79.

Chaudhuri, K.N., Ghosh, B., Tepfer, D., Jha, S., 2006. Spontaneous plant regeneration in transformed roots and calli from Tylophora indica: changes in morphological phenotype and tylophorine accumulation associated with transformation by Agrobacterium rhizogenes. Plant Cell Rep. 25 (10), 1059-1066.

Chericoni, S., Testai, L., Calderone, V., Flamini, G., Nieri, P., Morelli, I., Martinotti, E., 2003. The xanthones gentiacaulein and gentiakochianin are responsible for the vasodilator action of the roots of Gentiana kochiana. Planta Med. 69 (8), 770-772.

Choi, Y.H., Tapias, E.C., Kim, H.K., Lefeber, A.W.M., Erkelens, C., Verhoeven, J.T.J., Brzin, J., Zel, J., Verpoorte, R., 2004. Metabolic discrimination of Catharanthus roseus leaves infected by Phytoplasma using 1H-NMR spectroscopy and multivariate data analysis. Plant Physiol. 135 (4), 2398-2410. 
Dixit, N., Baboota, S., Kohli, K., Ahmad, S., Ali, J., 2007. Silymarin: a review of pharmacological aspects and bioavailability enhancement approaches. Indian J. Pharmacol. 39, 172-179.

Dubrovina, A.S., Kiselev, K.V., Veselova, M.V., Isaeva, G.A., Fedoreyev, S.A., Zhuravlev, Y.N., 2009. Enhanced resveratrol accumulation in rolB transgenic cultures of Vitis amurensis correlates with unusual changes in CDPK gene expression. J. Plant Physiol. 166, 1194-1206.

Gangopadhyay, M., Dewanjee, S., Chakraborty, D., Bhattacharya, S., 2011. Role of exogenous phytohormones on growth and plumbagin accumulation in Plumbago indica hairy roots and conservation of elite root clones via synthetic seeds. Ind. Crops Prod. 33 (2), 445-450.

Ge, H.X., Zhang, J., Lu, L.L., Yu, B.Y., 2014. Biotransformation of tetrahydroprotoberberines by Panax ginseng hairy root culture. J. Mol. Catal., B Enzym. 110, 133-139.

Grech-Baran, M., Sykłowska-Baranek, K., Krajewska-Patan, A., Wyrwał, A., Pietrosiuk, A., 2014. Biotransformation of cinnamyl alcohol to rosavins by non-transformed wild type and hairy root cultures of Rhodiola kirilowii. Biotechnol. Lett. 36 (3), 649-656.

Huang, S.H., Vishwakarma, R.K., Lee, T.T., Chan, H.S., Tsay, H.S., 2014. Establishment of hairy root lines and analysis of iridoids and analysis of iridoids and secoiridoids in the medicinal plant Gentiana scabra. Bot. Stud. 55, 17-25.

Isaković, A., Janković, T., Harhaji, L., Kostić-Rajacić, S., Nikolić, Z., Vajs, V., Trajković, V., 2008. Antiglioma action of xanthones from Gentiana kochiana: mechanistic and structure-activity requirements. Bioorg. Med. Chem. 6 (10), 5683-5694.

Janković, T., Krstić-Milošević, D., Aljančić, I., Šavikin, K., Menković, N., Radanović, D., Milosavljević, S., 2009. Phytochemical re-investigation of Gentiana utriculosa. Nat. Prod. Res. 23, 466-469.

Jiao, J., Gai, Q.-Y., Wang, W., Zang, Y.-P., Niu, L.-L., Fu, Y.-J., Wang, X., 2018. Remarkable enhancement of flavonoid production in a co-cultivation system of Isatis tinctoria L. Hairy root cultures and immobilized Aspergillus niger. Ind. Crops Prod. 112, 252-261.

Jovanović-Dunjić, R., 1977. Flora SR Srbije, vol 5, SANU, Belgrade.

Kado, C.I., Liu, S.T., 1981. Rapid procedure for detection and isolation of large and small plasmids. J. Bacteriol. 145 (3), 1365-1373.

Karak, S., Nag, G., De, B., 2017. Metabolic profile and $\beta$-glucuronidase inhibitory property of three species of Swertia. Rev. Bras. Farmacogn. 27 (1), 105-111.

Kawaguchi, K., Hirotani, M., Yoshikawa, T., Furuya, T., 1990. Biotransformation of digitoxigenin by ginseng hairy root cultures. Phytochemistry 29 (3), 837-843.

Kim, D.H., Jin, Y.H., Park, J.B., Kobashi, K., 1994. Silymarin and its components are inhibitors of $\beta$-glucuronidase. Biol. Pharm. Bull. 17, 443-445.

Köhlein, F., 1991. In: Jermyn, J. (Ed.), Gentians. Tiber Press, Portland, Oregon, USA.

Lacroix, B., Tzfira, T., Vainstein, A., Citovsky, V., 2006. A case of promiscuity: agrobac terium's endless hunt for new partners. Trends Genet. 22, 29-37.

Linsmaier, E.M., Skoog, F., 1965. Organic growth factor requirement of tobacco tissue cultures. Physiol. Plant. 18, 100-128.

Martin, K.P., Sabovljevic, A., Madassery, J.J., 2011. High-frequency transgenic plant regeneration and plumbagin production through methyl jasmonate elicitation from hairy roots of Plumbago indica L.. Crop Sci. Biotechnol. 14 (3), 205-212.

Matveeva, T.V., Sokornova, S.V., 2016. Agrobacterium rhizogenes-mediated transformation of plants for improvement of yields of secondary metabolites. In: Pavlov, A., Bley, T. (Eds.), Bioprocessing of Plant In Vitro Systems. Reference Series in Phytochemistry. Springer, Cham, pp. 161-202.

Mauro, M.L., Costantino, P., Bettini, P.P., 2017. The never ending story of rol genes: a century after. Plant Cell Tiss. Organ Cult. 131, 201-212.

Menković, N., Juranić, Z., Stanojković, T., Raonić-Stevanović, T., Šavikin, K., Zdunić, G., Borojević, N., 2010. Radioprotective activity of Gentiana lutea extracts and mangiferin. Phytother. Res. 24, 1693-1696.

Mishiba, K., Nishihara, M., Abe, Y., Nakatsu, T., Kawamura, H., Kodama, K., Takesawa, T., Abe, J., 2006. Production of dwarf potted gentian using wild-type Agrobacterium rhizogenes. Plant Biotechnol. 23, 33-38.

Mitić, N., Dmitrović, S., Djordjević, M., Zdravković-Korać, S., Nikolić, R., Raspor, M., Djordjević, T., Maksimović, V., Živković, S., Krstić-Milošević, D., Stanišić, M., Ninković, S., 2012. Use of Chenopodium murale L. Transgenic hairy root in vitro culture system as a new tool for allelopathic assays. J. Plant Physiol. 169 (12), 1203-1211.

Momčilović, I., Grubišić, D., Kojić, M., Nešković, M., 1997. Agrobacterium rhizogenes-mediated transformation and plant regeneration of four Gentiana species. Plant Cell Tissue Organ Cult. 50, 1-6.

Murashige, T., Skoog, F., 1962. A revised medium for rapid growth and bioassays with tobacco tissue cultures. Physiol. Plant. 15, 473-497.

Murray, M.G., Thompson, W.F., 1980. Rapid isolation of high molecular weight plant DNA. Nucleic Acids Res. 8, 4321-4325.

Noungoue Tchamo, D., Cartier, G., Dijoux-Franca, M.G., Tsamo, E., Mariotte, A.-M., 2001. Xanthones and other constituents of Trema orientalis. Pharm. Biol. 39 (3), 202-205.

Ohara, A., Daimon, H., Momota, Y., Dong, P.C., Masahiro, M., 2012. Plant regeneration from Crotalaria spectabilis hairy roots which showed in- hibited growth of root-knot nematodes (Meloidogyne hapla and M. incognita) in vitro. Plant Biotechnol. 29, 425-430.

Opabode, J.T., 2006. Agrobacterium-mediated transformation of plants: emerging factors that influence efficiency. Biotechnol. Mol. Biol. 1, 12-20.

Pradhan, S.C., Girish, C., 2006. Hepatoprotective herbal drug, silymarin from experimental pharmacology to clinical medicine. Indian J. Med. Res. 124, 491-504.

Šavikin, K., Menković, N., Zdunić, G., Stević, T., Radanović, D., Janković, T., 2009. Antimicrobial activity of Gentiana lutea L. Extracts. Z. Naturforsch 64 (5-6), 339-342.

Sevón, N., Oksman-Caldentey, K.M., 2002. Agrobacterium rhizogenes-mediated transformation: root cultures as a source of alkaloids. Planta Med. 68, 859-868.

Srivastava, V., Mehrotra, S., Mishra, S., 2017. Biotransformation through hairy roots: perspectives, outcomes, and major challenges. In: Jha, S. (Ed.), Transgenesis and Secondary Metabolism. Reference Series in Phytochemistry. Springer, Cham, pp. 347-370.

Suginuma, C., Akihama, T., 1995. Transformation of Gentiana with Agrobacterium rhizogenes. Acta Hortic. 392, 153-160.

Taneja, J., Jaggi, M., Wankhede, D.P., Sinha, A.K., 2010. Effect of loss of T-DNA genes on MIA biosynthetic pathway gene regulation and alkaloid accumulation in Catharanthus roseus hairy roots. Plant Cell Rep. 29, 1119-1129.

Tepfer, D., 1984. Transformation of several species of higher plants by Agrobacterium rhizogenes: sexual transmission of the transformed genotype and phenotype. Cell 37, 959-967.

Tepfer, D., 1990. Genetic transformation using Agrobacterium rhizogenes. Physiol. Plant. 79, 140-146.

Tepfer, M., Casse-Delbart, F., 1987. Agrobacterium rhizogenes as a vector for transforming higher plants. Microbiol. Sci. 4, 24-28.

Thomas, T.D., 2008. The role of activated charcoal in plant tisssue culture. Biotech. Adv. 26, 618-631.

Tomić, M., Tovilović, G., Butorović, B., Krstić, D., Janković, T., Aljančić, I., Menković, N., 2005. Neuropharmacological evaluation of diethylether extracts and xanthones of Gentiana kochiana. Pharmacol. Biochem. Behav. 81, 535-542.

Tutin, T.G., 1972. Flora Europea. Cambridge University Press, London.

Van Larebeke, N., Genetello, C.H., Hernalsteens, J.P., De Picker, A., Zaenen, I., Messens, E., Van Montagu, M., Schell, J., 1977. Transfer of Ti plasmids between Agrobacterium strains by mobilization with the conjugative plasmid RP4. Mol. Gen. Genet. 152, 1119-1124.

Veena, V., Taylor, C.G., 2007. Agrobacterium rhizogenes: recent developments and promising applications. In Vitro Cell. Dev. Biol., Plant 43 (5), 383-403.

Verma, P.C., Rahman, L., Negi, A.S., Jain, D.C., Khanuja, S.P.S., Banerjee, S., 2007. Agrobacterium rhizogenes mediated transformation of Picrorhiza kurroa Royle ex Benth: establishment and selection of superior hairy root clone. Plant Biotechnol. Rep. $1,169-174$.

Verma, P.C., Singh, H., Negi, A.S., Saxena, G., Rahman, L., Banerjee, S., 2015. Yield enhancement strategies for the production of picroliv from hairy root culture of Pi crorhiza kurroa Royle ex Benth. Plant Signal. Behav. 10 (5).

Vinterhalter, B., Orbović, V., Vinterhalter, D., 1999. Transgenic root cultures of Gentiana punctata L. Acta Soc. Bot. Pol. Pol. Tow. Bot. 68 (4), 275-280.

Vinterhalter, B., Momčilović, I., Vinterhalter, D., 2000. High biomass producing root cultures of Gentiana punctata L. Transformed with Agrobacterium tumefaciens C58C1 (pArA4b). Arch. Biol. Sci. Belgrade 52 (2), 85-90.

Vinterhalter, B., Krstić-Milošević, D., Janković, T., Pljevljakušić, D., Ninković, S., Smigocki, A., Vinterhalter, D., 2015. Gentiana dinarica Beck. Hairy root cultures and evaluation of factors affecting growth and xanthone production. Plant Cell Tiss. Organ Cult. 121, 667-679.

Vinterhalter, B., Mitić, N., Vinterhalter, D., Uzelac, B., Krstić-Milošević, D., 2016. Somatic embryogenesis and in vitro shoot propagation of Gentiana utriculosa. Biologia 71 (2), 139-148.

Wang, D., Song, Y., Chen, Y., Yao, W., Li, Z., Liu, W., Yue, S., Wang, Z., 2013. Metabolic pools of phenolic acids in Salvia miltiorrhiza are enhanced by co-expression of Antirrhinum majus Delila and Rosea1 transcription factors. Biochem. Eng. J. 74, 115-120.

Wu, H.J., Wang, X.X., Li, Y., Zhang, D.G., Zhang, B., Wang, X.Y., 2011. Propagation of Gentiana macrophylla (Pall) from hairy root explants via indirect somatic embryogenesis and gentiopicroside content in obtained plants. Acta Physiol. Plant. 33 (6), 2229-2237.

Yang, D.C., Choi, Y.E., 2000. Production of transgenic plants of Panax ginseng from Agrobacterium-transformed hairy roots. Plant Cell Rep. 19, 491-496.

Zhang, H.L., Xue, S.H., Pu, F., Tiwari, R.K., Wang, X.Y., 2010. Establishment of hairy root lines and analysis of gentiopicroside in the medicinal plant Gentiana macrophylla. Russ. J. Plant Physiol. 57, 110-117.

Zhao, S.-J., Wang, J.-H., Liang, Y.-L., Xu, L.-X., 2012. Somatic embryogenesis and plantlet regeneration from hairy roots transformed by Agrobacterium rhizogenes in Panax quinquefolium L. Int. J. Biomed. Pharmaceut. Sci. 6, 97-100. 